\title{
HISTÓRIA MUNDIAL DAS BIBLIOTECAS: DA MESOPOTÂMIA ANTIGA AO JAPÃO MODERNO DA PRIMEIRA DÉCADA DO SÉCULO XXI.
}

CAMPBELL, James W. P. A; PRYCE, Will. A biblioteca: uma história mundial. Tradução de Thais Rocha. São Paulo: SESC, 2016. 328 p.

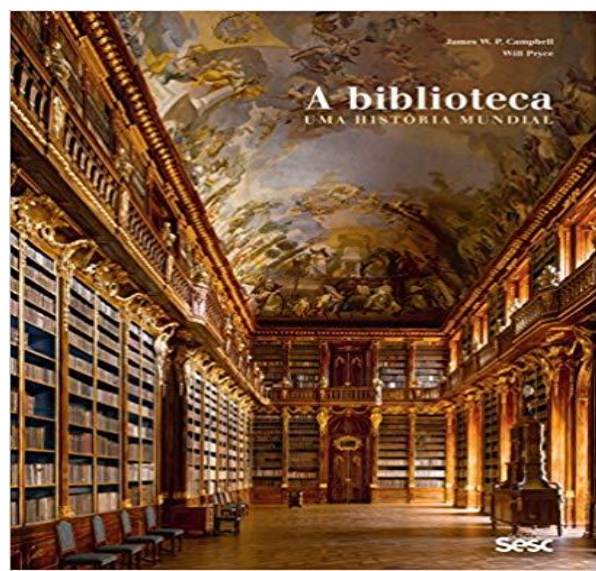

\section{Resumo}

Resenha do livro A biblioteca: uma história mundial de James W.P. Campbell e Will Pryce. Após três anos de pesquisa percorrendo mais de 80 bibliotecas pelo mundo, os autores apresentam a história mundial das bibliotecas, bem como as arquiteturas exuberantes, destinadas aos ricos e poderosos que nelas investiram pesadamente, desde a Mesopotâmia antiga ao Japão moderno da primeira década do século XXI. Portanto, quanto ao futuro das bibliotecas na era eletrônica e suas arquiteturas, ainda é muito cedo para estabelecer qualquer perspectiva.

Palavras-chave: História mundial das bibliotecas. Arquitetura exuberante. Perspectivas das bibliotecas.

Ao longo de suas 328 páginas divididas em oito capítulos, além de prefácio e introdução, apresentados em um acabamento gráfico primoroso, destaca-se a seleção das imagens. A obra retrata a história das bibliotecas pelo mundo com suas arquiteturas exuberantes, tornando-as verdadeiras obras de arte desde a Antiguidade aos dias atuais. Logo no prefácio:

A ironia é que nos dizem que os livros e, portanto, as bibliotecas estão ameaçadas. Então, será que este estudo servirá apenas como memorial de um tipo de construção extinto? Talvez, mas ainda não. Hoje em dia, mais e mais livros estão sendo impressos todos os anos em uma quantidade nunca vista antes (CAMPBELL; PRYCE, 2016, p. 15).

$\mathrm{Na}$ introdução da obra há contextualização do que é biblioteca e a ambiguidade que essa palavra nos traz nas línguas indo-europeias, assim como definição de seus espaços, afirmando que eles vão além da guarda e preservação de livros. Em sua concepção, estas são erguidas para mostrar ao mundo a ambição acadêmica dos indivíduos e das organizações, o que, tratando-se de bibliotecas públicas, caracteriza um gesto de caridade. Discorre ainda sobre os capítulos que compõem a obra, além de explanar os motivos que os levaram a escrevê-la. Por conseguinte, há poucas publicações que tratam das bibliotecas e suas arquiteturas.

No primeiro capítulo, "Começos perdidos", entrelaça a história das bibliotecas desde os primórdios da escrita, em Urak, na Mesopotâmia Antiga, onde eram utilizadas tábuas de argila para registro de pagamentos, "quem pagou o quê, para quem e quando" (CAMPBELL; PRYCE, 2016, p. 37), até a queda do Império Romano. É importante 
ressaltar a humildade científica dos pesquisadores, quando estes dizem que a Biblioteca de Elba não deve ser a mais antiga do mundo, "mas é certamente, até hoje, o melhor exemplo descoberto e preservado" (CAMPBELL; PRYCE, 2016, p. 38). É elogiável essa sobriedade, pois não há um consenso, até o momento, sobre qual é a biblioteca mais antiga. Alguns pesquisadores afirmam ser a de Assurbanipal, e outros, a de Elba. Destarte, embora não haja consenso, a Biblioteca de Elba destaca-se no cenário da história.

No segundo capítulo, "Claustros, códices e baús", a pesquisa percorre as bibliotecas da Idade Média, a partir da queda do Império Romano até o Renascimento. Antes de irmos adiante, gostaria de ressaltar que as bibliotecas desse período não apresentaram avanços significativos para a humanidade, porquanto eram destituídas de caráter público. Fato interessante é que nessa época, as maiores bibliotecas não estavam na Europa cristã, mesmo porque a tecnologia de impressão de livros não existia nesse continente. Por essa razão, o capítulo em questão inicia-se pela Tripitaka Koreana, que nas palavras da Organização das Nações Unidas para a Educação, a Ciência e a Cultura (UNESCO), há nessa biblioteca "o corpus mais importante e completo de textos da doutrina budista do mundo" (CAMPBELL; PRYCE, 2016, p. 61). Logo, é de relevância nesse capítulo, pois esclarece importantes construções arquitetônicas e acervos em regiões pouco conhecidas pelas pesquisas.

O terceiro capítulo, "Armários, correntes e baias", compreende a Reforma da Europa, de 1500 a 1600. Porém, com enfoque nas bibliotecas chinesas, porque nesse período as construções das bibliotecas estavam à frente das europeias e sobre o fato de que pouco se sabe sobre elas. "A mais antiga biblioteca intacta da China está na Câmara Tianyi, em Ningob, a $150 \mathrm{~km}$ ao sul de Xangai, por volta de 1561" (CAMPBELL; PRYCE, 2016, p. 91). Nela há uma inscrição que não permite a entrada de ninguém de fora, nem mesmo um parente do Fan Qin tem autorização para retirar um livro do seu acervo. Os autores finalizam esse capítulo com a Biblioteca da Queen's College, no Reino Unido, e o seu atípico sistema de baia. Desse modo, na Europa, percebe-se um leve avanço acerca das bibliotecas e seus acervos nesse continente.

No quarto capítulo, "Muros, domos e alcovas", há a discussão sobre os sistemas de armazenamento dos livros no século XVII. Notadamente, inicia-se uma nova fase a caminho da modernidade, visto que nesse período os valores das obras começaram a cair, levando bibliotecas a tomarem providências, como por exemplo, a Escorial, de 1585, na Espanha. Os autores afirmam que "não existe nada parecido com a Escorial, nem Windsor, na Inglaterra, nem Peterhof, na Rússia, nem Versalhes, na França" (CAMPBELL; PRYCE, 2016, p. 121). E termina apresentando a Biblioteca de Codrigton, 1751, no Reino Unido, como uma obra-prima no mundo e, consequentemente, esse avanço deve-se aos preços das obras e em razão de as bibliotecas terem expandido suas construções e seus sistemas de preservação e guarda.

$\mathrm{O}$ quinto capítulo, "Anjos, afrescos e portas secretas" trata sobre as bibliotecas barrocas e rococós do século XVIII. As bibliotecas são comparadas com as que existiram em diferentes épocas, apresentando pontos capazes de singularizar essas distinções, por exemplo: bibliotecas criadas na Europa que são verdadeiros "campos de batalhas entre a Igreja e o Iluminismo" (CAMPBELL; PRYCE, 2016, p. 153), movimento de intelectuais que defendia o uso da razão, liberdade política e econômica. De um lado, estava a Igreja e o Estado indissociáveis e, de outro, a provocação de nova ciência. Dessa maneira, dentre várias bibliotecas com essas características, destacase a Biblioteca Casanatense, de 1710, em Roma, Itália.

O sexto capítulo, "Estantes de ferro, luminárias a gás e fichas de catalogação" enfatiza as bibliotecas do século XIX, caracterizadas por dois fatores importantes: suas expansões exigidas pela produção de livros cada vez mais rápida e o surgimento das primeiras bibliotecas independentes, ou seja, de caráter público. Nessa época "A Associação Americana de Bibliotecas (ALA) propiciou um lugar para bibliotecários e arquitetos compartilharem suas experiências e ponto de vista" (CAMPBELL; PRYCE, 2016, p. 243). Logo, os modelos neoclássicos predominavam nas bibliotecas pelo mundo, inclusive nas nacionais, porém a Biblioteca 
Nacional do Brasil é um exemplo tardio do neoclassicismo.

No sétimo capítulo, "Eletricidade, concreto e aço" são caracterizadas as bibliotecas do século XX, marcado pela "explosão no projeto de bibliotecas, especialmente nos Estados Unidos" (CAMPBELL; PRYCE, 2016, p. 249). Contudo, continuaram a ser projetadas nos modelos tradicionais até a metade do século, quando, a partir daí, projetos modernistas foram criados. Merece destaque o fato de que apesar desse período ser marcado por duas grandes guerras, não houve prejuízo para o desenvolvimento de construções arquitetônicas para o abrigo de acervos. Prova disso, foram as grandes bibliotecas erguidas no Japão e no Leste Europeu.

No oitavo e último capítulo, "O futuro das bibliotecas na era eletrônica", os autores, com muita cautela, informam que ainda é muito cedo para estabelecer perspectivas quanto aos projetos arquitetônicos e ao futuro das bibliotecas neste início de século. $\mathrm{O}$ surgimento de computadores, de textos eletrônicos e a crise econômica produziram vários debates sobre o "fim das bibliotecas como instituição social" (CAMPBELL; PRYCE, 2016, p. 289). Porém, é uma discussão antagônica, tendo em vista o grande número de edificações erguidas e outras que se encontram em construção na primeira década deste século. "Para um setor que se diz em crise, parece estar incrivelmente saudável" (CAMPBELL; PRYCE, 2016, p. 289). Portanto, as grandes construções erguidas e em construção demonstram que o setor não está em crise como muitos indicam ou muito menos confirmam a previsão do fim das bibliotecas.

Ao concluirmos a relevância de contribuição da referida obra, recomendamos sua leitura aos docentes e discentes de arquitetura e biblioteconomia, historiadores e bibliotecários e qualquer cidadão que tenha interesse, em especial, pela arquitetura e pela história mundial das bibliotecas. E, portanto, contribuindo com grandeza para o rigor da pesquisa científica apresentada, resgatando a historicidade da arquitetura das bibliotecas, focando espaço, época e construções dos eventos ocorridos até os dias atuais. THE FIRST DECADE OF THE 21ST CENTURY

\begin{abstract}
Review of the book Library: a world history of James W P Campbell and Will Pryce. After three years of research covering more than 80 libraries around the world, the authors present the world history of libraries, as well as the lush architectures, destined for the rich and powerful that have invested heavily in them, since the ancient Mesopotamia to the modern Japan from the first decade of the 21st century. So, about the future of libraries in the electronic age and its architecture is still very early to establish any perspective.
\end{abstract}

Keywords: World history of libraries. Exuberant architecture. Perspectives of libraries.

\title{
REFERÊNCIAS
}

CAMPBELL, James W. P. A biblioteca: uma história mundial. Fotografia de Will Pryce e tradução de Thais Rocha. São Paulo: SESC, 2016. 328 p. 